Research Paper

\title{
Association of Far-Infrared Radiation Therapy and Ankle-Brachial Index of Patients on Hemodialysis with Peripheral Artery Occlusive Disease
}

Szu-Chia Chen"1,2,4,6, Mei-Yueh Lee ${ }^{1,3,6}$, Jiun-Chi Huang1,2,4, I-Ching Kuo1,2, Hsiu-Chin Mai5, Po-Lin Kuo ${ }^{1,7}$, Jer-Ming Chang ${ }^{2,8}$, Shang-Jyh Hwang 2,6, Hung-Chun Chen ${ }^{2,6}$

1. Graduate Institute of Clinical Medicine, College of Medicine, Kaohsiung Medical University, Kaohsiung, Taiwan;

2. Division of Nephrology,

3. Division of Endocrinology and Metabolism, Department of Internal Medicine, Kaohsiung Medical University Hospital, Kaohsiung Medical University, Kaohsiung, Taiwan;

4. Department of Internal Medicine, Kaohsiung Municipal Hsiao-Kang Hospital, Kaohsiung Medical University, Kaohsiung, Taiwan;

5. Department of Nursing, Kaohsiung Municipal Hsiao-Kang Hospital, Kaohsiung Medical University, Kaohsiung, Taiwan;

6. Faculty of Medicine, College of Medicine, Kaohsiung Medical University, Kaohsiung, Taiwan;

7. Institute of Medical Science and Technology, National Sun Yat-Sen University, Kaohsiung, Taiwan;

8. Department of Internal Medicine, Kaohsiung Municipal Cijin Hospital (Operated by Kaohsiung Medical University), Kaohsiung, Taiwan.

$\triangle$ Corresponding author: Jer-Ming Chang, MD, PhD, Department of Internal Medicine, Kaohsiung Municipal Cijin Hospital (Operated by Kaohsiung Medical University), 33 Cigang Rd, Cijin District, Kaohsiung 805, Taiwan. TEL: 886- 7- 5711188; E-mail : jemich@kmu.edu.tw.

( ) Ivyspring International Publisher. Reproduction is permitted for personal, noncommercial use, provided that the article is in whole, unmodified, and properly cited. See http://ivyspring.com/terms for terms and conditions.

Received: 2016.08.24; Accepted: 2016.11.01; Published: 2016.12.07

\begin{abstract}
Background and Aim: The ankle-brachial index $(\mathrm{ABI})$ is recognized to be a good marker for atherosclerosis, and is useful in the diagnosis of peripheral artery occlusive disease (PAOD) which is prevalent among patients on hemodialysis (HD).

Methods: This randomized trial aimed to evaluate the effect of far-infrared radiation (FIR) therapy on $A B I$ in $H D$ patients with PAOD. PAOD was defined as patients with $A B I<0.95$. One hundred and eight HD patients were enrolled, including 50 in the control group and 58 in the FIR group. A WS TY101 FIR emitter was applied for 40 minutes during each HD session, three times per week for six months. The ABI was measured before and after the FIR therapy.

Results: Regardless of FIR therapy, the bilateral $A B I$ decreased (in the FIR group, left: $0.88 \pm 0.22$ to $0.85 \pm 0.24, p=0.188$; right: $0.92 \pm 0.20$ to $0.90 \pm 0.23, p=0.372$; in control group, left: $0.91 \pm 0.23$ to $0.88 \pm 0.21, p=0144$; right: $0.93 \pm 0.17$ to $0.89 \pm 0.21, p=0.082$ ). Multivariate logistic analysis of the FIR group revealed that high uric acid (odds ratio [OR]: 2.335; $95 \%$ confidence interval $[\mathrm{Cl}]$ : 1.117-4.882; $p=0.024$ ) and aspirin use (OR: $16.463 ; 95 \% \mathrm{Cl}: 1.787-151.638 ; p=0.013$ ) were independently associated with increased bilateral $A B I$ after FIR therapy.

Conclusions: This study demonstrates that $A B I$ is not increased after FIR therapy in HD patients with PAOD. However, in the FIR group, patients with higher uric acid level or those who used aspirin have increased bilateral $A B I$ after FIR therapy.
\end{abstract}

Key words: ankle-brachial index; peripheral artery occlusive disease; far-infrared therapy; hemodialysis.

\section{Introduction}

The incidence of non-traumatic lower-extremity amputation among patients with end-stage renal disease (ESRD) is higher than that in non-ESRD patients (1). The most common indication for amputation in the ESRD population is peripheral artery occlusive disease (PAOD), which is associated with increased cardiovascular mortality, morbidity, and hospitalization $(2,3)$. At the same time, the ankle-brachial index (ABI) was found to be a good marker for atherosclerosis and is useful in diagnosing PAOD. Ono et al. (4) evaluated the all-cause and cardiovascular morality among patients on 
hemodialysis (HD) using $\mathrm{ABI}$ and found that a reduction in ABI predicted poor survival.

The pathophysiology of atherosclerotic lesions is multifaceted and complicated. These lesions are composed of stable atherosclerotic plaques (rich in extracellular matrix and smooth muscle cells) and unstable plaques (rich in macrophages, foam cells, and fibrous cap which is weak and prone to rupture) $(5,6)$. The classical medical management of atherosclerosis involves the modification of risk factors, medical therapy (i.e., anti-platelet drugs, cilostazol, and statins), and regular exercise (7). However, these therapies have not been systematically applied to ESRD patients. Furthermore, the optimal management of PAOD in ESRD patients is quite controversial, and other therapies are needed to effectively treat stenosis of the lower-extremity among HD patients with PAOD.

Far-infrared radiation (FIR) uses electromagnetic waves at wavelengths of 5.6 to $1000 \mu \mathrm{m}$ (8). This therapy may improve endothelial function and reduce the severity of certain cardiovascular diseases $(9,10)$. Moreover, some studies indicate that FIR therapy can improve the access flow and survival of arteriovenous fistula (AVF) in patients on HD, as well as the access maturation and patency of newly-created AVF in patients with chronic kidney disease (CKD) stages 4 and $5(11,12)$. The most common cause of AVF failure is stenosis at the venous anastomosis due to abnormal neointimal proliferation and extracellular matrix deposition (13). These changes are also observed in classic atheroma, suggesting that atherosclerotic lesions and venous stenosis in AVF may share similar pathogenic mechanisms $(14,15)$.

The technology of FIR has been applied in a variety of fields, including treatment of ischemic lesions and skin tissue necrosis due to trauma and diabetes. Whether FIR therapy can improve PAOD awaits further confirmation. For this purpose, this study aimed to evaluate the effect of FIR on ABI in HD patients with PAOD.

\section{Patients and Methods}

\section{Study Patients and Design}

This prospective randomized controlled trial study was conducted in three HD clinics in southern Taiwan. The inclusion criteria of patients were: 1) having received maintenance HD therapy for at least 3 months; 2) age >20 years; 3) receiving regular anti-hypertensive drugs or oral hypoglycemic agents for at least 1 month; 4) patients with PAOD were defined as those with ABI $<0.95$ (16). Patients who refused any ABI-form device examination $(n=5)$, those with atrial fibrillation $(n=4)$, Those with bilateral below-knee amputation $(\mathrm{n}=2)$, and those with hospitalization or antibiotic treatment in the last 4 weeks $(n=5)$ were excluded. (Figure 1 )

A total of 116 patients were enrolled from August to September 2015. All of the patients received HD three times per week within the study period for six months (October 2015 to March 2016). Each HD session was performed for 3.5-4.5 hours, with a blood flow rate of $250-300 \mathrm{~mL} / \mathrm{min}$ and dialysate flow of 500 $\mathrm{mL} / \mathrm{min}$. Blood samples were taken before and after $\mathrm{HD}$ to calculate $\mathrm{Kt} / \mathrm{V}$ (17). The patients were randomly allocated to either the FIR group or the control group (1:1) via computerized minimization algorithm to ensure balance between the two groups.

\section{Ethics statement}

The study protocol was approved by the Institutional Review Board of Kaohsiung Medical University Hospital KMUH-IRB-2014-04-06(I). Written informed consent was obtained from the patients, and all clinical investigations were conducted according to the principles expressed in the Declaration of Helsinki. The patients also consented to the publication of the clinical details.

\section{FIR Therapy}

In this study, a WS TY101 FIR emitter (WS Far Infrared Medical Technology Co., Ltd., Taipei, Taiwan) was used for FIR therapy. The electrified ceramic plates of this emitter generated electromagnetic waves at wavelengths of 5 and $12 \mu \mathrm{m}$ (peak at $8.2 \mu \mathrm{m}$ ). The top radiator was set at a height of $25 \mathrm{~cm}$ above the surface of both lower legs, with treatment time set at 40 min during each HD session. The patients received ABI from an ABI-form and questionnaire. Follow-up ABI and questionnaire were obtained after six months of FIR therapy.

Demographic and medical data, including age, sex, and co-morbidities were obtained from medical records and patient interviews. Fasting blood sugar were obtained from samples using an auto-analyzer (Roche Diagnostics GmbH, D-68298 Mannheim COBAS Integra 400). The Kt/V was evaluated as a marker of dialysis and determined according to the Daugirdas procedure [17]. Efficacy was assessed using a pain visual analog scale (VAS).

\section{Assessment of ABI}

The values of $\mathrm{ABI}$ were measured 10-30 min before $\mathrm{HD}$. The ABI were measured using an ABI-form device that automatically and simultaneously measured blood pressure in both arms and ankles using an oscillometric method (18). Briefly, occlusion and monitoring cuffs were placed tightly around the upper arm without blood access and on both lower extremities with the patient in a 
supine position. The ABI was calculated by the ratio of the ankle systolic blood pressure divided by the arm systolic blood pressure. The ABI measurements were done twice for each patient.

\section{Statistical analysis}

Statistical analysis was performed using the SPSS 17.0 for Windows (SPSS Inc. Chicago, USA). Data are expressed as percentages, mean \pm standard deviation, mean \pm standard error of the mean for VAS

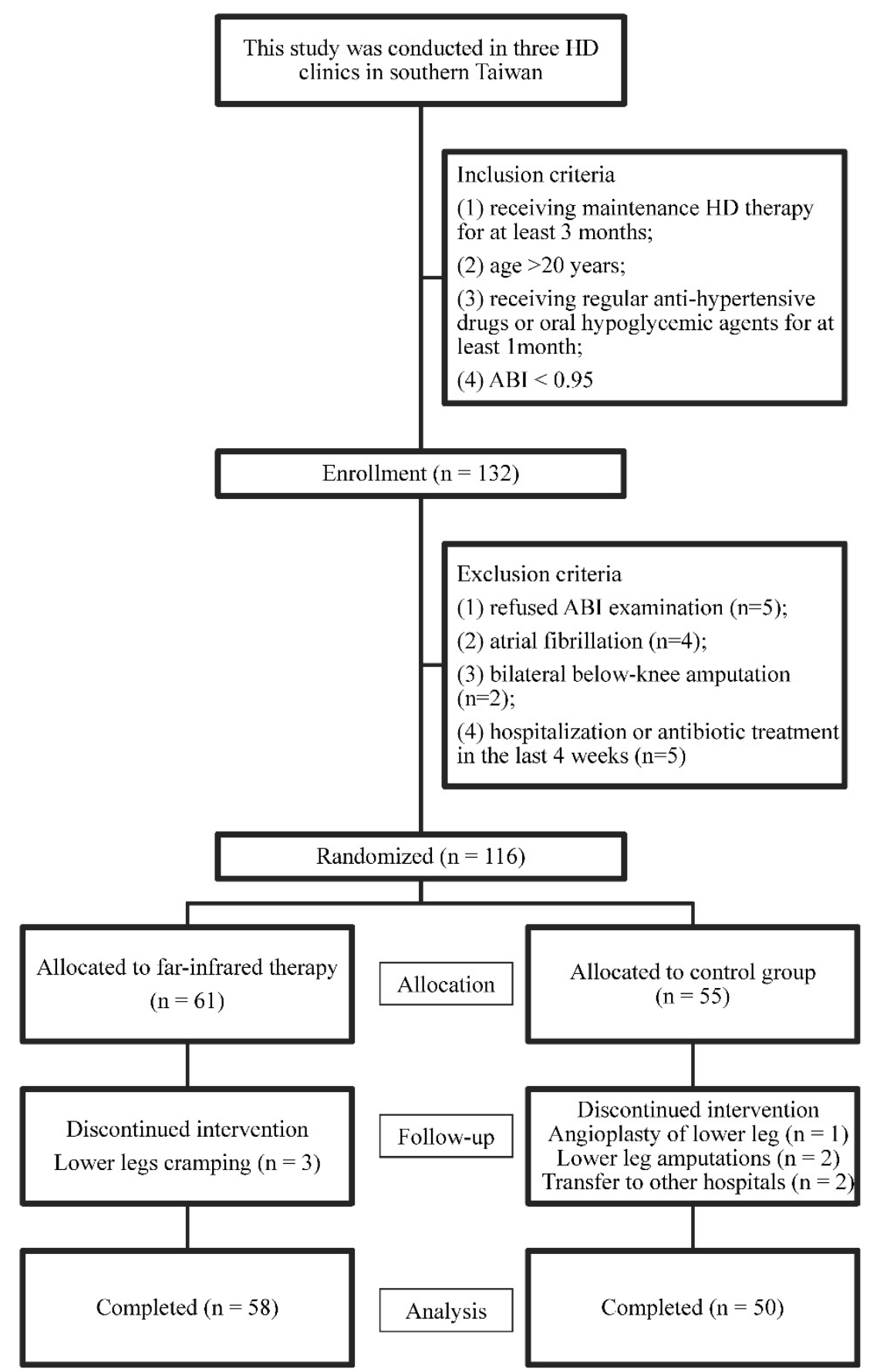

Figure 1. Flow chart of study participants for the randomized controlled trial to evaluate the effect of far infrared therapy on PAOD in hemodialysis patients. scores, or median $\left(25^{\text {th }}-75^{\text {th }}\right.$ percentile) for duration of dialysis and triglyceride. Differences between groups were analyzed by Chi-square test for categorical variables, by independent t-test for continuous variables with approximately-normal distribution, and by Mann-Whitney $U$ test for continuous variables with skewed distribution. Paired t-test was used to compare ABI change before and after the FIR therapy. Variables with a $p<0.2$ by univariate analysis were selected for multivariate logistic regression analysis to identify factors associated with bilateral ABI increase after FIR therapy. Statistical significance was set at $p<0.05$.

\section{Results}

As shown in Fig 1, a total of 116 patients were enrolled in the study, of which 55 patients were randomly distributed to the control group and 61 patients, to the far infrared treatment group. During follow-up, one patient received angioplasty for the lower extremity, two underwent lower leg amputations, three developed lower leg cramping, and two patients were transferred to another hospital. This study ended on March 2016. One hundred and eight patients completed the study, with 58 patients in the FIR group and 50 in the control group. Their mean age was $63.1 \pm 11.9$ years old. Comparison of baseline characteristics between the FIR and control groups was shown in Table 1.

\section{$A B I$ changes before and after FIR therapy}

Changes in ABI before and after FIR therapy were shown in Table 2. In the FIR group, ABI decreased in both the left (from $0.88 \pm 0.22$ to $0.85 \pm 0.24, p=0.188$ ) and the right (from $0.92 \pm 0.20$ to $0.90 \pm 0.23, p=0.372$ ) legs. Similarly, in the control group (without FIR therapy), $\mathrm{ABI}$ also decreased in both the left (from $0.91 \pm 0.23$ to $0.88 \pm 0.21$, $p=0144$ ) and right (from $0.93 \pm 0.17$ to $0.89 \pm 0.21, p=0.082)$ legs. The mean VAS score decreased from $2.05 \pm 0.23$ at baseline to $1.80 \pm 0.29$ 
$(p<0.001)$ at 6 months later after FIR therapy in FIR group.

\section{Determinants of bilateral $A B I$ increase}

A comparison of the clinical characteristics between patients with bilateral $\mathrm{ABI}$ increase and those without an increase in the FIR therapy was shown in Table 3. Compared to patients without bilateral ABI increase, those with bilateral ABI increase had higher total calcium and higher uric acid levels. Table 4 showed the odds ratio (OR) estimates for bilateral ABI increase after adjustments for duration of dialysis, diabetes mellitus, albumin, total cholesterol, creatinine, total calcium, uric acid, and aspirin use. In the multivariate logistic analysis, high uric acid (OR: 2.335; 95\% confidence interval [CI]: 1.117-4.882; $p=$ $0.024)$ and aspirin use (OR: 16.463; 95\% CI: $1.787-151.638 ; p=0.013)$ were independently associated with bilateral ABI increase after FIR therapy.

Table 1. Comparison of baseline characteristics between patients with and without FIR therapy.

\begin{tabular}{|c|c|c|c|c|}
\hline Characteristics & $\begin{array}{l}\text { All patients } \\
(\mathrm{n}=108)\end{array}$ & $\begin{array}{l}\text { With FIR therapy } \\
(\mathrm{n}=58)\end{array}$ & $\begin{array}{l}\text { Without FIR therapy } \\
(\mathrm{n}=50)\end{array}$ & $p$ \\
\hline Age (year) & $63.1 \pm 11.9$ & $63.2 \pm 11.6$ & $63.0 \pm 12.4$ & 0.954 \\
\hline Male gender $(\%)$ & 52.8 & 48.3 & 58.0 & 0.313 \\
\hline Duration of dialysis (years) & $4.7(2.0-8.0)$ & $4.7(2.4-8.4)$ & $4.5(1.8-4.7)$ & \\
\hline Smoking history (\%) & 36.1 & 32.8 & 40.0 & 0.435 \\
\hline Diabetes mellitus (\%) & 66.7 & 72.4 & 60.0 & 0.172 \\
\hline Hypertension (\%) & 58.3 & 63.8 & 52.0 & 0.215 \\
\hline Coronary artery disease (\%) & 12.0 & 5.2 & 20.0 & 0.035 \\
\hline Cerebrovascular disease (\%) & 10.2 & 10.3 & 10.0 & 0.953 \\
\hline Systolic blood pressure (mmHg) & $157.5 \pm 27.1$ & $154.8 \pm 26.8$ & $160.6 \pm 27.5$ & 0.277 \\
\hline Diastolic blood pressure (mmHg) & $80.5 \pm 16.2$ & $78.1 \pm 16.3$ & $83.3 \pm 15.8$ & 0.095 \\
\hline Body mass index $\left(\mathrm{kg} / \mathrm{m}^{2}\right)$ & $24.2 \pm 3.7$ & $24.3 \pm 3.8$ & $24.2 \pm 3.5$ & 0.889 \\
\hline \multicolumn{5}{|l|}{$\mathrm{ABI}$} \\
\hline Left & $0.89 \pm 0.23$ & $0.88 \pm 0.22$ & $0.91 \pm 0.23$ & 0.843 \\
\hline Right & $0.92 \pm 0.20$ & $0.92 \pm 0.20$ & $0.93 \pm 0.17$ & 0.799 \\
\hline \multicolumn{5}{|l|}{ Laboratory parameters } \\
\hline Albumin (g/dL) & $3.91 \pm 0.31$ & $3.94 \pm 0.30$ & $3.88 \pm 0.33$ & 0.293 \\
\hline Fasting glucose (mg/dL) & $154.2 \pm 82.7$ & $168.0 \pm 91.1$ & $138.8 \pm 70.0$ & 0.096 \\
\hline Triglyceride (mg/dL) & $144(92-253)$ & $143(98.8-277.5)$ & $146(85.5-220.5)$ & 0.326 \\
\hline Total cholesterol (mg/dL) & $176.8 \pm 37.9$ & $179.7 \pm 36.3$ & $173.3 \pm 39.9$ & 0.388 \\
\hline HDL-cholesterol (mg/dL) & $39.9 \pm 11.1$ & $41.8 \pm 12.0$ & $37.9 \pm 9.8$ & 0.180 \\
\hline LDL-cholesterol (mg/dL) & $92.3 \pm 31.9$ & $96.6 \pm 32.6$ & $88.2 \pm 31.2$ & 0.271 \\
\hline Hemoglobin (g/dL) & $10.9 \pm 1.4$ & $10.9 \pm 1.2$ & $10.9 \pm 1.6$ & 0.853 \\
\hline Creatinine (mg/dL) & $9.8 \pm 2.1$ & $10.1 \pm 1.9$ & $9.5 \pm 2.3$ & 0.116 \\
\hline Total calcium (mg/dL) & $9.5 \pm 0.9$ & $9.6 \pm 0.9$ & $9.4 \pm 0.9$ & 0.110 \\
\hline Phosphorous (mg/dL) & $4.8 \pm 1.2$ & $4.9 \pm 1.0$ & $4.8 \pm 1.4$ & 0.689 \\
\hline $\begin{array}{l}\text { Calcium-phosphorous product } \\
\left(\mathrm{mg}^{2} / \mathrm{dL}^{2}\right)\end{array}$ & $46.0 \pm 12.1$ & $46.8 \pm 9.6$ & $45.0 \pm 14.6$ & 0.449 \\
\hline Uric acid (mg/dL) & $7.2 \pm 1.3$ & $7.5 \pm 1.3$ & $6.8 \pm 1.2$ & 0.006 \\
\hline Kt/V (Daugirdas) & $1.60 \pm 0.27$ & $1.65 \pm 0.29$ & $1.54 \pm 0.25$ & 0.032 \\
\hline \multicolumn{5}{|l|}{ Medications } \\
\hline Aspirin use & 23.1 & 20.7 & 26.0 & 0.514 \\
\hline ACEI and/or ARB use & 19.4 & 17.2 & 22.0 & 0.533 \\
\hline$\beta$-blocker use & 22.2 & 15.5 & 30.0 & 0.071 \\
\hline Calcium channel blocker use & 24.1 & 22.4 & 26.0 & 0.664 \\
\hline Statin use & 25.0 & 25.9 & 24.0 & 0.824 \\
\hline
\end{tabular}

Abbreviations. ABI, ankle-brachial index; baPWV, brachial-ankle pulse wave velocity; HDL, high-density lipoprotein; LDL, low-density lipoprotein; ACEI, angiotensin converting enzyme inhibitor; ARB, angiotensin II receptor blocker.

Table 2. ABI changes of patients with and without FIR therapy.

\begin{tabular}{|c|c|c|c|c|}
\hline \multirow[t]{2}{*}{ Parameters } & \multicolumn{2}{|c|}{ With FIR therapy } & \multicolumn{2}{|c|}{ Without FIR therapy } \\
\hline & Before & After & Before & After \\
\hline \multicolumn{5}{|l|}{ ABI } \\
\hline Left & $0.88 \pm 0.22$ & $0.85 \pm 0.24$ & $0.91 \pm 0.23$ & $0.88 \pm 0.21$ \\
\hline Right & $0.92 \pm 0.20$ & $0.90 \pm 0.23$ & $0.93 \pm 0.17$ & $0.89 \pm 0.21$ \\
\hline
\end{tabular}

Abbreviations. ABI, ankle-brachial index; baPWV, brachial-ankle pulse wave velocity. 
Table 3. Comparison of baseline characteristics between patients with bilateral $A B I$ improvement or not in patients with FIR therapy

\begin{tabular}{|c|c|c|c|}
\hline Characteristics & $\begin{array}{l}\text { Not bilateral ABI improvement } \\
(\mathrm{n}=44)\end{array}$ & $\begin{array}{l}\text { Bilateral ABI improvement } \\
(\mathrm{n}=14)\end{array}$ & $p$ \\
\hline Age (year) & $63.6 \pm 11.3$ & $61.9 \pm 12.7$ & 0.649 \\
\hline Male gender $(\%)$ & 47.7 & 50 & 0.882 \\
\hline Duration of dialysis (years) & $4.2(2.0-7.2)$ & $7.3(4.7-13.6)$ & 0.131 \\
\hline Smoking history (\%) & 31.8 & 35.7 & 0.787 \\
\hline Diabetes mellitus (\%) & 77.3 & 57.1 & 0.142 \\
\hline Hypertension (\%) & 61.7 & 71.4 & 0.544 \\
\hline Coronary artery disease (\%) & 4.5 & 7.1 & 0.999 \\
\hline Cerebrovascular disease (\%) & 9.1 & 14.3 & 0.624 \\
\hline Systolic blood pressure (mmHg) & $155.0 \pm 25.8$ & $154.5 \pm 30.7$ & 0.957 \\
\hline Diastolic blood pressure (mmHg) & $77.0 \pm 17.0$ & $81.6 \pm 14.0$ & 0.355 \\
\hline Body mass index $\left(\mathrm{kg} / \mathrm{m}^{2}\right)$ & $24.0 \pm 3.7$ & $25.0 \pm 4.4$ & 0.426 \\
\hline \multicolumn{4}{|l|}{$\mathrm{ABI}$} \\
\hline Left & $0.87 \pm 0.23$ & $0.92 \pm 0.18$ & 0.546 \\
\hline Right & $0.92 \pm 0.22$ & $0.92 \pm 0.14$ & 0.989 \\
\hline \multicolumn{4}{|l|}{ Laboratory parameters } \\
\hline Albumin (g/dL) & $3.91 \pm 0.30$ & $4.06 \pm 0.24$ & 0.101 \\
\hline Fasting glucose $(\mathrm{mg} / \mathrm{dL})$ & $173.8 \pm 93.1$ & $143.4 \pm 82.5$ & 0.374 \\
\hline Triglyceride (mg/dL) & $141(97.3-250.5)$ & $175.5(122-306.5)$ & 0.231 \\
\hline Total cholesterol (mg/dL) & $175.5 \pm 38.1$ & $192.9 \pm 26.7$ & 0.120 \\
\hline HDL-cholesterol (mg/dL) & $43.2 \pm 12.4$ & $39.5 \pm 11.4$ & 0.425 \\
\hline LDL-cholesterol (mg/dL) & $96.5 \pm 34.8$ & $96.7 \pm 28.8$ & 0.988 \\
\hline Hemoglobin $(\mathrm{g} / \mathrm{dL})$ & $10.9 \pm 1.2$ & $11.1 \pm 1.5$ & 0.538 \\
\hline Creatinine $(\mathrm{mg} / \mathrm{dL})$ & $9.9 \pm 2.0$ & $10.8 \pm 1.7$ & 0.134 \\
\hline Total calcium (mg/dL) & $9.5 \pm 0.8$ & $10.1 \pm 0.9$ & 0.048 \\
\hline Phosphorous (mg/dL) & $4.9 \pm 0.9$ & $4.9 \pm 1.3$ & 0.984 \\
\hline Calcium-phosphorous product $\left(\mathrm{mg}^{2} / \mathrm{dL}^{2}\right)$ & $46.3 \pm 9.3$ & $48.4 \pm 10.8$ & 0.502 \\
\hline Uric acid (mg/dL) & $7.2 \pm 1.2$ & $8.4 \pm 1.2$ & 0.001 \\
\hline Kt/V (Daugirdas) & $1.67 \pm 0.31$ & $1.58 \pm 0.19$ & 0.313 \\
\hline \multicolumn{4}{|l|}{ Medications } \\
\hline Aspirin use & 15.9 & 35.7 & 0.110 \\
\hline ACEI and/or ARB use & 18.2 & 14.3 & 0.999 \\
\hline$\beta$-blocker use & 13.6 & 27.3 & 0.673 \\
\hline Calcium channel blocker use & 22.7 & 21.4 & 0.999 \\
\hline Statin use & 20.5 & 42.9 & 0.095 \\
\hline
\end{tabular}

Abbreviations. ABI, ankle-brachial index; baPWV, brachial-ankle pulse wave velocity; HDL, high-density lipoprotein; LDL, low-density lipoprotein; ACEI, angiotensin converting enzyme inhibitor; ARB, angiotensin II receptor blocker.

Table 4. Determinants for bilateral $A B I$ improvement in patients with FIR therapy using binary logistic regression analysis.

\begin{tabular}{|c|c|c|}
\hline \multirow[t]{2}{*}{ Parameters } & \multicolumn{2}{|l|}{ Multivariate adjusted } \\
\hline & odds ratio $(95 \% \mathrm{CI})$ & $p$ \\
\hline Duration of dialysis (log per 1 year) & $2.469(0.160-38.028)$ & 0.517 \\
\hline Diabetes mellitus & $0.556(0.071-4.325)$ & 0.575 \\
\hline \multicolumn{3}{|l|}{ Laboratory parameters } \\
\hline Albumin (per $0.1 \mathrm{~g} / \mathrm{dL}$ ) & $1.181(0.874-1.597)$ & 0.278 \\
\hline Total cholesterol (per $1 \mathrm{mg} / \mathrm{dL}$ ) & $1.020(0.993-1.047)$ & 0.157 \\
\hline Creatinine (per $1 \mathrm{mg} / \mathrm{dL}$ ) & $1.078(0.643-1.807)$ & 0.775 \\
\hline Total calcium (per $1 \mathrm{mg} / \mathrm{dL}$ ) & $1.737(0.645-4.677)$ & 0.275 \\
\hline Uric acid (per $1 \mathrm{mg} / \mathrm{dL}$ ) & $2.335(1.117-4.882)$ & 0.024 \\
\hline Aspirin use & $16.463(1.787-151.638)$ & 0.013 \\
\hline
\end{tabular}

\section{Discussion}

The present study evaluated the effect of FIR therapy on ABI in HD patients with PAOD. The results showed that $A B I$ decreased, not increased, after FIR therapy. However, in the FIR group, patients with higher uric acid level and those who took aspirin had bilateral ABI increase after FIR therapy.

Evaluating the effect of FIR therapy on AVF, Lin et al. found that FIR therapy increased access flow of
AVF and improved the survival of AVF in HD patients after FIR therapy for one year (11). They also found that FIR therapy improved the access flow, maturation, and patency of newly-created AVF in patients with advanced CKD after FIR therapy for one year (12). The findings were attributed to both the thermal effect-induced vasodilation and the non-thermal effects of inhibiting intimal hyperplasia, thereby improving endothelial dysfunction. However, the present study did not observe the effects of FIR 
therapy on ABI in HD patients with PAOD. There are several possible reasons. First, the FIR therapy was just for six months in this study, while the study by Lin had FIR therapy for one year $(11,12)$. Second, the studied vessels in two studies were completely different. The AVF is located in the superficial site of the upper extremity, whereas the occluded artery of PAOD is in the deeper site of the lower extremity. Third, the pathogenetic mechanisms of stenosis in AVFs and PAOD are different. The development of neointimal hyperplasia in AVF includes surgical trauma at the time of arteriovenous surgery, hemodynamic sheer stress at the vein-artery or vein-graft anastomosis, injuries from routine needle punctures, and repeated balloon angioplasties. These mechanisms are different from those involved in the arterial atherosclerosis in PAOD. Lastly, it's very probable that the occlusion level of PAOD resides in the more proximal sites, not just in the lower extremity. In the present study, the radiator was set at a height of $25 \mathrm{~cm}$ above the surface of both lower legs. The occluded vessels might not have been exposed to the FIR therapy. In our opinion, shorter FIR therapy duration, deeper occluded vessels, different mechanisms of stenosis, or the failure to expose occluded vessels to FIR therapy might explain the negative results.

Another important finding of this study is that HD patients with higher uric acid level have bilateral ABI increase after FIR therapy. However, the mechanism by which uric acid is associated with atherosclerotic disease remains unclear. Uric acid may increase platelet adhesiveness, or urate crystals may be associated with increased platelet lysis (19-21). Uric acid may also play a role in the formation of free radicals and in oxidative stress $(22,23)$. Moreover, hyperuricemia per se can induce endothelial dysfunction by inhibiting the synthesis and release of nitric oxide (24). The renin-angiotensin system in vascular endothelial cells (a hormonal vasoconstriction system) is also activated by elevated uric acid (25). A previous experiment has confirmed that the solubility of monosodium urate falls sharply with decreasing temperature (26). Local temperature may partially explain the clinically observed distribution of gouty tophi and gouty arthritis. FIR therapy is a form of heat therapy, which may allow multiple energy transfer to as deep as 2 to $3 \mathrm{~cm}$ into subcutaneous tissue (27). Data from animal models have shown that FIR therapy improves vascular endothelial function through up-regulating of endothelial nitric oxide synthase (9). Furthermore, non-thermal effects of FIR therapy have been shown to inhibit vascular inflammation by inducing heme oxygenase-1 to increase skin microcirculation (28).
Presumably, urate deposition in the lower extremity of patients with PAOD during cold temperatures and urate-related atherosclerosis may improve after FIR therapy. This may play a role in the clinically observed increase of ABI after FIR therapy in HD patients with hyperuricemia, implying a novel impact of FIR therapy on PAOD among different groups.

This study has some limitations. First, although the study patients were randomly assigned by controlling as many factors as possible, individual variations of vascular conditions could still influence the results. A large-scale, prospective, randomized, controlled trial is still warranted to evaluate the effect of FIR therapy on PAOD in HD patients. Second, subacute occlusion may stimulate the growth of a collateral circulation, which supply the regions distal to the blood occlusion. The function of the occluded artery is thereby partially, sometimes completely, restored. ABI may not be truly reflective of the degree of obstruction. Lastly, it is very difficult to quantify, standardize the FIR therapy, and tailor the treatment to individual need.

In conclusion, this study demonstrates that $\mathrm{ABI}$ is not increased after FIR therapy in HD patients with PAOD. However, in the FIR group, patients with higher uric acid and those who use aspirin have increased bilateral ABI after FIR therapy. Therefore, FIR therapy may be a helpful tool for improving PAOD in those specific patients.

\section{Acknowledgement}

The research presented in this article is supported by the grants from the Ministry of Science and Technology (MOST 105-2314-B-037-016), and Kaohsiung Municipal Hsiao-Kang Hospital (kmhk-104-001), Kaohsiung Medical University, Kaohsiung, Taiwan.

We thank Kaohsiung Municipal Ta-Tung Hospital and the Ming-Kang HD clinic for the inclusion of patients in this study.

We thank WS FAR IR Medical Technology CO., LTD, who provided the machines of WS Far-infrared Therapy Unit, TY-101F.

\section{Conflict of interest}

There is no conflict of interest in the information contained in the manuscript.

\section{References}

1. Eggers PW, Gohdes D, Pugh J. Nontraumatic lower extremity amputations in the medicare end-stage renal disease population. Kidney Int 1999; 56:1524-33.

2. Dumaine RL, Montalescot G, Steg PG, Ohman EM, Eagle K, Bhatt DL. Renal function, atherothrombosis extent, and outcomes in high-risk patients. Am Heart J 2009; 158:141-8

3. Rajagopalan S, Dellegrottaglie S, Furniss AL, Gillespie BW, Satayathum S, Lameire N, Saito A, Akiba T, Jadoul M, Ginsberg N, Keen M, Port FK, Mukherjee D, Saran R. Peripheral arterial disease in patients with end-stage 
renal disease: Observations from the dialysis outcomes and practice patterns study (dopps). Circulation 2006; 114:1914-22.

4. Ono K, Tsuchida A, Kawai H, Matsuo H, Wakamatsu R, Maezawa A, Yano S, Kawada T, Nojima Y. Ankle-brachial blood pressure index predicts all-cause and cardiovascular mortality in hemodialysis patients. J Am Soc Nephrol 2003; 14:1591-8.

5. Finn AV, Nakano M, Narula J, Kolodgie FD, Virmani R. Concept of vulnerable/unstable plaque. Arterioscler Thromb Vasc Biol 2010; 30:1282-92.

6. Ross R. Atherosclerosis--an inflammatory disease. New Engl J Med 1999; 340:115-26.

7. Hiatt WR. Medical treatment of peripheral arterial disease and claudication. New Engl J Med 2001; 344:1608-21.

8. Toyokawa H, Matsui Y, Uhara J, Tsuchiya H, Teshima S, Nakanishi H, Kwon AH, Azuma Y, Nagaoka T, Ogawa T, Kamiyama Y. Promotive effects of far-infrared ray on full-thickness skin wound healing in rats. Exp Biol Med (Maywood) 2003; 228:724-9.

9. Ikeda Y, Biro S, Kamogawa Y, Yoshifuku S, Eto H, Orihara K, Yu B, Kihara T, Miyata M, Hamasaki S, Otsuji Y, Minagoe S, Tei C. Repeated sauna therapy increases arterial endothelial nitric oxide synthase expression and nitric oxide production in cardiomyopathic hamsters. Circ J 2005; 69:722-9.

10. Kihara T, Biro S, Ikeda Y, Fukudome T, Shinsato T, Masuda A, Miyata M, Hamasaki S, Otsuji Y, Minagoe S, Akiba S, Tei C. Effects of repeated sauna treatment on ventricular arrhythmias in patients with chronic heart failure. Circ J 2004; 68:1146-51.

11. Lin CC, Chang CF, Lai MY, Chen TW, Lee PC, Yang WC. Far-infrared therapy: A novel treatment to improve access blood flow and unassisted patency of arteriovenous fistula in hemodialysis patients. J Am Soc Nephrol 2007; 18:985-92.

12. Lin CC, Yang WC, Chen MC, Liu WS, Yang CY, Lee PC. Effect of far infrared therapy on arteriovenous fistula maturation: An open-label randomized controlled trial. Am J Kidney Dis 2013; 62:304-11.

13. Weiss MF, Scivittaro V, Anderson JM. Oxidative stress and increased expression of growth factors in lesions of failed hemodialysis access. Am J Kidney Dis 2001; 37:970-80.

14. Hofstra L, Tordoir JH, Kitslaar PJ, Hoeks AP, Daemen MJ. Enhanced cellular proliferation in intact stenotic lesions derived from human arteriovenous fistulas and peripheral bypass grafts. Does it correlate with flow parameters? Circulation 1996; 94:1283-90.

15. Ross R. The pathogenesis of atherosclerosis: A perspective for the 1990s. Nature 1993; 362:801-9.

16. Guo X, Li J, Pang W, Zhao M, Luo Y, Sun Y, Hu D. Sensitivity and specificity of ankle-brachial index for detecting angiographic stenosis of peripheral arteries. Circ J 2008; 72:605-10.

17. Daugirdas JT. Simplified equations for monitoring kt/v, pcrn, ekt/v, and epcrn. Adv Ren Replace Ther 1995; 2:295-304.

18. Yamashina A, Tomiyama H, Takeda K, Tsuda H, Arai T, Hirose K, Koji Y, Hori S, Yamamoto Y. Validity, reproducibility, and clinical significance of noninvasive brachial-ankle pulse wave velocity measurement. Hypertens Res 2002; 25:359-64.

19. Emmerson BT. Atherosclerosis and urate metabolism. Aust N Z J Med 1979; 9:451-4.

20. Newland H. Hyperuricemia in coronary, cerebral and peripheral arterial disease: An explanation. Med Hypotheses 1975; 1:152-5.

21. Ginsberg MH, Kozin F, O'Malley M, McCarty DJ. Release of platelet constituents by monosodium urate crystals. J Clin Invest 1977; 60:999-1007.

22. Vasquez-Vivar J, Santos AM, Junqueira VB, Augusto O. Peroxynitrite-mediated formation of free radicals in human plasma: Epr detection of ascorbyl, albumin-thiyl and uric acid-derived free radicals. Biochem J 1996; 314 ( Pt 3):869-76.

23. Anker SD, Leyva F, Poole-Wilson PA, Kox WJ, Stevenson JC, Coats AJ. Relation between serum uric acid and lower limb blood flow in patients with chronic heart failure. Heart 1997; 78:39-43.

24. Khosla UM, Zharikov S, Finch JL, Nakagawa T, Roncal C, Mu W, Krotova K, Block ER, Prabhakar S, Johnson RJ. Hyperuricemia induces endothelial dysfunction. Kidney Int 2005; 67:1739-42.

25. Kanellis J, Feig DI, Johnson RJ. Does asymptomatic hyperuricaemia contribute to the development of renal and cardiovascular disease? An old controversy renewed. Nephrology (Carlton) 2004; 9:394-9.

26. Loeb JN. The influence of temperature on the solubility of monosodium urate. Arthritis Rheum 1972; 15:189-92.

27. Hartel M, Hoffmann G, Wente MN, Martignoni ME, Buchler MW, Friess H. Randomized clinical trial of the influence of local water-filtered infrared a irradiation on wound healing after abdominal surgery. Br J Surg 2006; 93:952-60

28. Lin CC, Liu XM, Peyton K, Wang H, Yang WC, Lin SJ, Durante W. Far infrared therapy inhibits vascular endothelial inflammation via the induction of heme oxygenase-1. Arterioscler Thromb Vasc Biol 2008; 28:739-45. 